\title{
Knowledge and attitudes concerning medical genetics amongst physicians and medical students in Cameroon (sub-Saharan Africa)
}

Ambroise Wonkam, MD, Alfred K. Njamnshi, MD, and Fru F. Angwafo III, MD

\begin{abstract}
Purpose: Little is known about physician's knowledge of, and attitudes toward genetics in sub-Saharan Africa. Methods: Survey of 101 pre-clinical, 95 clinical medical students, and 110 physicians, in Cameroon. Results: The awareness of DNA diagnosis was poor: $0,2.2$, and $1.2 \%$, respectively, for sickle cell anemia. The majority of the respondents considered genetic counseling as indispensable (97.6, 98.9 and 100\%); and prenatal diagnosis as acceptable. The acceptance of medical abortion increased with the level of medical education (62.6, 74.7 and 90.7\%). Sickle cell anemia was considered as a "serious disease" by a greater majority of respondents than Down syndrome $(P<0.001)$. But, in all three groups, the acceptance of termination of affected pregnancy "if the respondent's own child was affected" was lower for sickle cell anemia than Down syndrome (22.4 versus 40.2\%, 10.8 versus $29.3 \%$ and 36.1 versus $70.4 \%$ ). Conclusions: The data suggest a poor knowledge of genetic tests among medical students and physicians. This cohort appears to accept the principles of medical genetics. Our data emphasized a need to introduce genetics and to develop research on its ethical and social implications in Cameroon. Genet Med 2006:8(6):331-338.
\end{abstract}

Key Words: genetics, knowledge and attitudes, physicians and medical students, prenatal diagnosis, sub-Saharan Africa

With the publication of the sequence of the human genome, medicine is in the midst of a revolution as new disease-related genes are being identified at a rapid rate. ${ }^{1}$ However, many scientists who are interested in the potential of genetic knowledge to improve health and to promote equity are concerned that the commercial development of genomics will widen the gap between the developed and the developing world. ${ }^{2}$ The recent World Health Organization (WHO) publication Genomics and World Health (2002) recognizes this concern. ${ }^{3}$

The most effective application of genetic knowledge is for early diagnosis and prevention. As prevention is a priority for the developing world, an effective means of bridging the gap between developed and developing countries would be therefore to introduce preventive genetic methods in developing countries, an appropriate point of entry for DNA technology. ${ }^{4}$ Nevertheless, scientists in both developed and developing countries, who are concerned about bridging the gap in genetic services, need to be aware of factors that could interfere with an objective vision of the specific needs of developing countries.

\footnotetext{
From the Department of Genetic Medicine and Development, Geneva University Hospitals, Geneva, Switzerland, and Faculty of Medicine and Biomedical Sciences, University of Yaoundé I, Yaoundé, Cameroon.

Dr Ambroise Wonkam, MD, Department of Genetic Medicine and Development, Geneva University Hospitals, Rue Michel-Servet1, CH 1211, Geneva 4, Switzerland.

Submitted for publication August 28, 2005.

Accepted for publication March 14, 2006.
}

DOI: 10.1097/01.gim.0000223542.97262.21
In general, disease prevention relies heavily on education of health professionals. ${ }^{5,4}$ Given the broad medical applications of molecular genetics, healthcare practitioners will have to become more involved in providing patient information about genetic testing, guide patients to a clinical genetic service, and deal with the consequences of patients' choices when tested. ${ }^{6}$

Little is known about physicians' knowledge of, and attitudes toward genetics or their awareness of the availability of tests for genetic disorders in sub-Saharan Africa. Furthermore, medical students represent the future leaders on medical issues in their communities, thus their knowledge and attitudes may influence how entire communities accept medical genetics. ${ }^{7}$ Cameroon is a sub-Saharan African country with a population of about 15 million but with no clinical genetics service. We focused on four genetic disorders: sickle cell anemia (SCA), Down's syndrome (DS), hemophilia (Hem), and Huntington's disease (HD), which we considered representative to examine the knowledge trends of medical students and physicians concerning medical genetics. We also examined their attitude toward using genetic counseling services, prenatal diagnosis and termination of affected pregnancy. This latter point is consistent with the goal of the World health Organization in its process of consultations to develop, especially in developing countries, an agenda in the area of Ethical, Legal and Social Implications (ELSI) of Genomic Research. ${ }^{3}$ 


\section{METHODS}

\section{Study sample}

We used the opportunity of the $20^{\text {th }}$ Cameroon National Medical Conference in 2002, an annual scientific congress for postgraduate continuing medical education, to randomly sample physicians irrespective of their practice location or specialties. Before administering the survey questionnaire at the reception desk of the medical conference, an introductory explanation stated the purpose of the survey: to assess knowledge of, and attitudes to medical genetics in the medical community of Cameroon. The completed questionnaires were collected at the end of the each of the three days of the conference. The response rate was $36.7 \%$ (110/300).

For medical students, the questionnaires were distributed in the amphitheatres and collected one hour later, in order to reduce bias due to readable information from textbooks that might have affected the knowledge evaluation. The response rate was $50.5 \%$ (101/200) for pre-clinical and 47.5\% (95/200) for clinical medical students. A unique sample format was used for medical students and physicians. Respondents' anonymity was respected.

\section{Survey format}

The survey questionnaire comprised three categories of questions: Socio-demographic characteristics, medical genetics knowledge, and potential use of a clinical genetics service.

Medical genetics knowledge: The respondent was asked to spontaneously write down three genetic diseases. Furthermore, for the four genetic diseases (SCA, DS, Hem, and HD) that we considered relevant in medical genetic practice, questions were asked on etiology, symptoms and signs, diagnosis and treatment options, inheritance, and evaluation of the degree of seriousness. Questions were all open-ended except for inheritance (multiplechoice questions). In the present article we focus on the evaluation of etiology, mode of inheritance and diagnostic methods.

Potential use of a clinical genetics service: The questions included, awareness and attitudes toward genetic counseling and testing, attitudes toward prenatal diagnosis and termination of affected pregnancy (or medical abortion), specifically "if the respondent's own child was affected" by a "serious malformation," DS or SCA.

Two clinical geneticists from the Division of Medical Genetics of the University of Geneva Medical School critically reviewed the questions. The pre-tested questionnaires took approximately 40 minutes to complete. The survey instrument is available upon request.

\section{Statistical analysis}

Data were analyzed using SPSS (Statistical Package for Social Sciences, Chicago, IL). Means were compared using non-parametric tests. The $P$-values were considered significant if they reached the $95 \%$ significance level.

\section{RESULTS}

\section{The sample population}

Three hundred six of 700 questionnaires were completed and included 101 pre-clinical, 95 clinical medical students and
Table 1

Respondents' demographic characteristics

\begin{tabular}{|c|c|c|c|c|}
\hline & $\begin{array}{l}\% \text { Pre- } \\
\text { clinical } \\
\text { medical } \\
\text { students } \\
(\mathrm{N}=101)\end{array}$ & $\begin{array}{c}\% \text { Clinical } \\
\text { medical } \\
\text { students } \\
(\mathrm{N}=95)\end{array}$ & $\begin{array}{l}\text { \% Physicians } \\
(\mathrm{N}=110)\end{array}$ & $P$-values \\
\hline Mean age (years) & $21.5 \pm 0.4^{a}$ & $23.7 \pm 0.6^{a}$ & $34.7 \pm 0.8^{a}$ & 0.001 \\
\hline Sex: Male & 64.4 & 65.2 & 81.1 & $0.01^{b}$ \\
\hline Practice Location & & & & 0.001 \\
\hline $\begin{array}{l}\text { University/Central } \\
\text { Hospital }\end{array}$ & & & 76.5 & \\
\hline Peripheral hospital & & & 33.3 & \\
\hline Religion & & & & NS \\
\hline Catholic & 52.6 & 48.8 & 54.4 & \\
\hline Protestant & 37.9 & 44 & 34 & \\
\hline Muslim & 7.4 & 6 & 1.9 & \\
\hline Traditional & 0 & 0 & 4.9 & \\
\hline No religion & 2.1 & 0 & 4.9 & \\
\hline Others & 0 & 1.2 & 0 & \\
\hline
\end{tabular}

${ }^{a}$ Number of years.

${ }^{b} P$-value when comparing physicians to medical students. NS, not significant.

110 physicians. Respondents were predominantly male. The majority in the physician group was under 40 years of age (Table 1) and identified themselves as general practitioners (GP): $42.6 \%$ (46/108). The distribution of other medical specialties was uneven: Gynecologist and obstetricians or residents in gynecology $13.9 \%$ (15/108) and surgery $13.9 \%$ (15/108) were the most represented groups.

\section{Genetic disease in respondents' families}

Twenty-one, 26.3, and $22.2 \%$, respectively, of pre-clinical and clinical medical students and physicians indicated to have at least one family member suffering from a genetic disease. These diseases included: SCA: 13.5\% (41/303), DS: 3.3\% (10/ 303), oculocutaneous albinism: 3\% (9/303).

At least one case of congenital malformation was said to be present in 9.3\% $(\mathrm{N}=101) ; 11.4 \%(\mathrm{~N}=88)$ and $16.2 \%(\mathrm{~N}=$ 105) of medical students' and physicians' families. Limb and finger malformations were the most prevalent at $7.3 \%(22 /$ $302)$, followed by congenital cardiac malformations (5/302), and digestive tract malformations (4/302).

\section{Genetic education and knowledge trends of four genetic diseases (SCA, DS, Hem, HD)}

To the question "Can you cite spontaneously three genetic diseases?" respondents cited a range of 85 different genetic diseases. Three hemoglobinopathies were cited among the top 10 diseases (Table 2).

Awareness of SCA and DS was higher than of that hemophilia. Awareness of Huntington's disease was poor. Surprisingly, physicians' knowledge trends were not so different from those of medical students (Table 3 ). 
Table 2

The top 10 spontaneously cited genetic conditions

\begin{tabular}{|c|c|c|c|c|}
\hline & $\begin{array}{c}\% \text { Pre-clinical } \\
\text { medical } \\
\text { students } \\
(\mathrm{N}=101)\end{array}$ & $\begin{array}{c}\text { \% Clinical } \\
\text { medical } \\
\text { students } \\
(\mathrm{N}=95)\end{array}$ & $\begin{array}{c}\text { \% Physicians } \\
(\mathrm{N}=110)\end{array}$ & $P$-values \\
\hline Sickle cell disease & 78.2 & 86.3 & 84.5 & NS \\
\hline Hemophilia & 61.4 & 55.8 & 55.5 & NS \\
\hline Down's syndrome & 57.4 & 45.3 & 55.5 & NS \\
\hline Albinism & 23.8 & 10.5 & 13.6 & $0.01^{a}$ \\
\hline $\begin{array}{l}\text { Klinefelter } \\
\text { syndrome }\end{array}$ & 13.9 & 20.0 & 5.5 & $0.002^{b}$ \\
\hline Thalassemia & 4.0 & 15.8 & 15.5 & $0.005^{a}$ \\
\hline Daltomism & 15.8 & 12.6 & 5.5 & NS \\
\hline Turner syndrome & 9.9 & 11.6 & 5.5 & NS \\
\hline Steinert's disease & 1.0 & 10.5 & 3.6 & NS \\
\hline G6PD deficiency & 0.0 & 3.2 & 9.1 & NS \\
\hline
\end{tabular}

NS, not significant.

${ }^{a} P$-values not significant when comparing clinical medical student and physicians.

${ }^{b} P$-values not significant when comparing pre-clinical and clinical medical student.

\section{Awareness of DNA diagnostic methods}

Awareness of DNA diagnosis was very poor (Table 3). For disorders where non-molecular genetic approaches are available, respondents favored these answers: For SCD, hemoglo- bin electrophoresis was the main diagnostic method recorded by $55.2 \%$ (37/67), $87.8 \%$ (79/90) $94.3 \%$ (100/106), respectively. Biological evaluation of hemophilic factor VIII and IX represented 37.6\% (12/32), 64.8\% (48/74) and 76.4\% (68/89) of respondents' answers obtained.

\section{Awareness of genetic counseling}

The awareness of genetic consultations was: $55.6 \%$ (55/99), $74.2 \%(69 / 93)$ and $86 \%$ (92/107) for the respective groups. The greater majority of the respondents considered a genetic counseling consultation as either indispensable or necessary in Cameroon (Fig. 1).

\section{Awareness of prenatal diagnosis and genetic testing in prenatal diagnosis}

Respectively, 95\%, 96.8\% and $100 \%$ of pre-clinical, clinical medical student and physicians are aware of prenatal diagnosis medicine.

The majority was aware of the use of ultrasonography (US) for prenatal diagnosis: 99\% (98/99), 100\% (91/91) and 100\% (108/108). In addition, 39.4\% (39/99), 58.9\% (53/ $90)$; and $90.5 \%$ (95/105), respectively, had "direct or indirect contact" with US.

Compared to the use of ultrasonography for prenatal diagnosis, a lower proportion was aware of the use of karyotype analysis in prenatal diagnosis: $87.9 \%$ (87/99), 88.9\% (80/90) and $92.4 \%(97 / 105)$; as well as DNA analysis $84.2 \%(80 / 95)$, $82.2 \%(74 / 90)$ and $87.6 \%(92 / 105)$, respectively.

Table 3

Evaluation of the best genetics knowledge trends about SCD, DS, Hem and $\mathrm{HD}^{a}$

\begin{tabular}{|c|c|c|c|c|}
\hline $\begin{array}{l}\text { Disease (Etiology, Diagnosis Mean, } \\
\text { Mode of Inheritance) }\end{array}$ & $\begin{array}{l}\text { Pre-clinical medical } \\
\text { students } \%(\mathrm{~N})\end{array}$ & $\begin{array}{l}\text { Clinical medical } \\
\text { students } \%(\mathrm{~N})\end{array}$ & Physicians \% (N) & $P$-values \\
\hline \multicolumn{5}{|l|}{ SCD } \\
\hline Glu6Val $\beta$-globin gene mutation & $29.7(27 / 91)$ & $36.2(34 / 94)$ & $46(46 / 100)$ & $0.001^{b}$ \\
\hline DNA diagnosis & $0(0 / 67)$ & $2.2(2 / 90)$ & $1.2(2 / 106)$ & $0.01^{b}$ \\
\hline Autosomal recessive & $69.6(64 / 92)$ & $81.3(74 / 91)$ & $75.2(76 / 101)$ & NS \\
\hline \multicolumn{5}{|l|}{ DS } \\
\hline 3 Chromosome 21 & $84.4(65 / 77)$ & $67.5(56 / 83)$ & $52.6(51 / 97)$ & $0.001^{c}$ \\
\hline Karyotype analysis & $72.1(31 / 43)$ & $78.3(54 / 69)$ & $80.4(74 / 92)$ & NS \\
\hline Non-mendelian & $39.2(29 / 74)$ & $46.2(30 / 65)$ & $29.8(28 / 94)$ & NS \\
\hline \multicolumn{5}{|l|}{ Hem } \\
\hline Mutation hemophilic factors genes A or B & $0(0 / 78)$ & $9.3(8 / 86)$ & $2.1(2 / 96)$ & NS \\
\hline DNA diagnosis & $3.1(1 / 32)$ & $5.4(4 / 74)$ & $4.5(4 / 89)$ & NS \\
\hline X-linked & $65.8(50 / 76)$ & $67.1(53 / 79)$ & $65(65 / 100)$ & NS \\
\hline \multicolumn{5}{|l|}{ HD } \\
\hline Genetic mutation & No data & $12.5(1 / 8)$ & $13(3 / 23)$ & NS \\
\hline DNA diagnosis & No data & $0(0 / 5)$ & $4.2(1 / 23)$ & NS \\
\hline Autosomal dominant & No data & $50(4 / 8)$ & $41.4(12 / 29)$ & NS \\
\hline
\end{tabular}

${ }^{a} \mathrm{SCD}$, sickle cell disease; DS, Down's syndrome; Hem, hemophilia; HD, Huntington's disease.

${ }^{b} P$-values not significant when comparing clinical medical student and physicians.

${ }^{c} P$-values not significant when comparing pre-clinical and clinical medical students. 

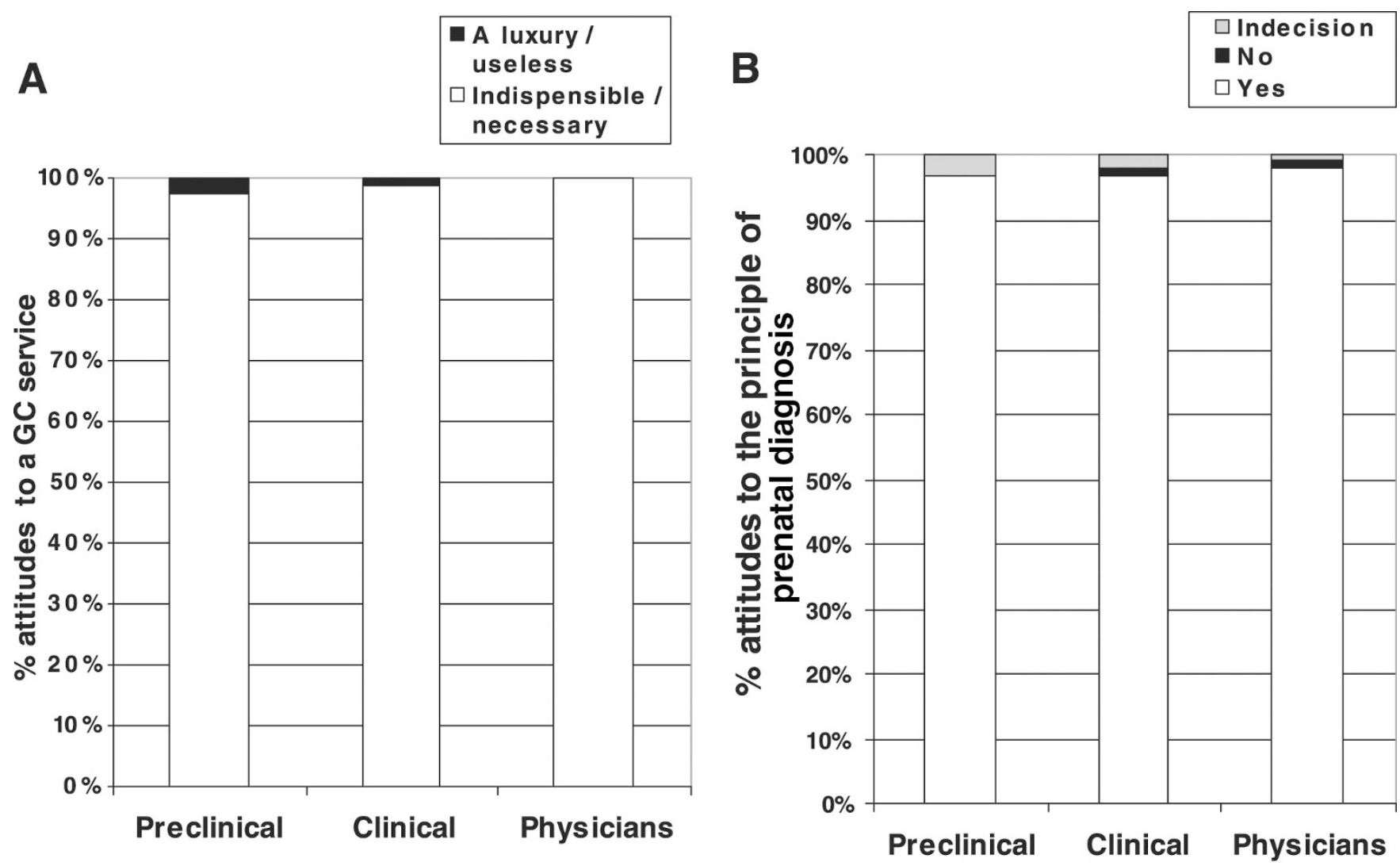

C

\begin{tabular}{|l|}
\hline$\square$ Indecision \\
$\square$ No \\
$\square$ Yes \\
\hline
\end{tabular}

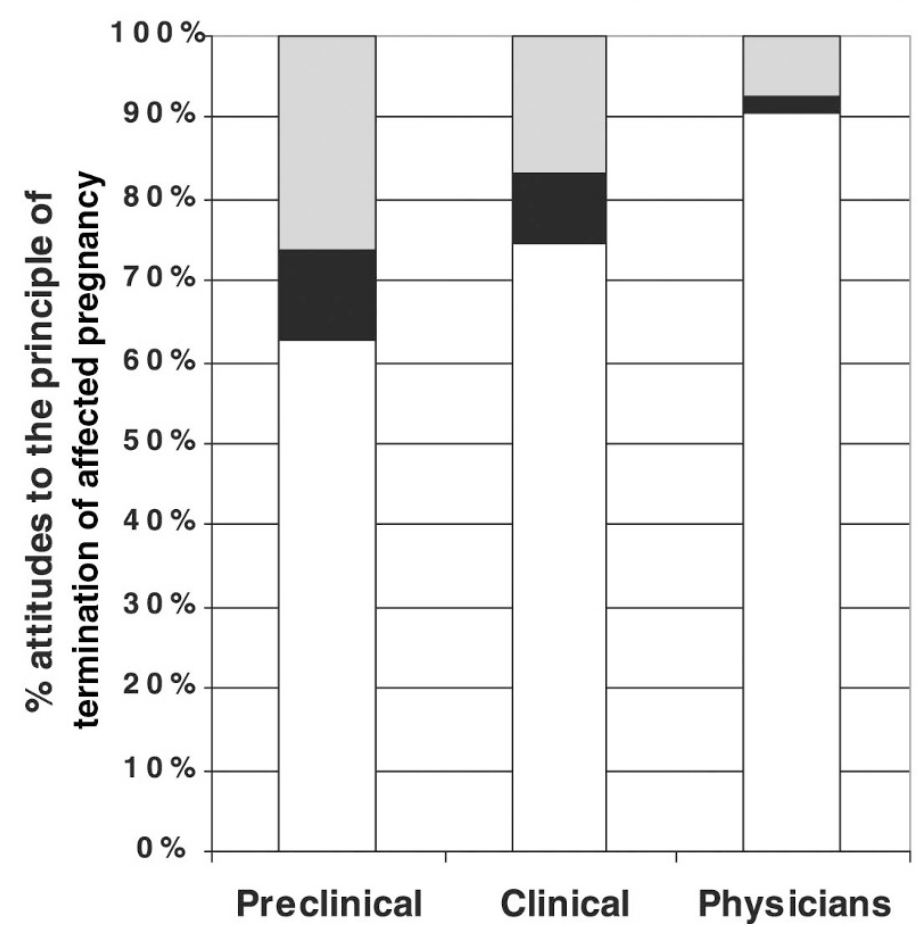

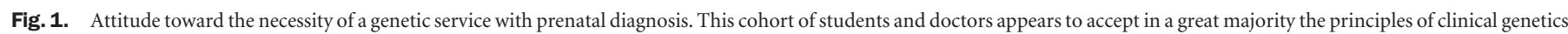

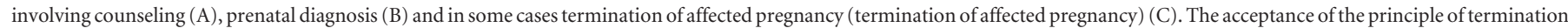
of affected pregnancy increases with the level of medical education $(P<0.001)$. 
Very few respondents "had any direct or indirect contact" with karyotype analysis: 9.1\% (9/99), 1.1\% (1/90), and 5.7\% (60/105), or DNA testing: 3.0\% (3/99), 1.1\% (1/90) and $0 \%$ (0/105), respectively.

\section{Attitudes to prenatal diagnosis and termination of pregnancy}

The majority of the respondents accepted the principle of prenatal diagnosis and the principle of termination of affected pregnancy (Fig. 1). Acceptance for termination of affected pregnancy increased with the level of medical education $(P<$ 0.001) (Fig. 1C). The acceptance of the principle of prenatal diagnosis varied with specific disease (Fig. 2A).

The acceptance of termination of affected pregnancy "if the respondent's own child" was affected by a "serious" malformation, DS or SCA was in the three groups lower than that of the principles of prenatal diagnosis $(P<0.001)$ or the general principle of termination of affected pregnancy $(P<0.001)$ (Fig. 2B).
The acceptance in principle of termination of affected pregnancy "if the respondent's own child" was affected by a "serious" malformation; DS or SCA was higher in the physicians' than in students' groups (Fig. 2B).

\section{The paradox between perception of seriousness and attitude to termination of affected pregnancy for SCA and DS}

SCA was considered as a "serious disease" by the greater majority of respondents and DS as "serious" by a lower proportion $(P<0.001): 96$ versus $64.6 \%, 97.8$ versus $80.8 \%$ and 94.4 versus $88 \%$. But, in all three groups, the acceptance of termination of affected pregnancies "if the respondent own child was affected" was lower for SCA than DS $(P<0.001)$ : 22.4 versus $40.2 \%, 10.8$ versus $29.3 \%$ and 36.1 versus $70.4 \%$ respectively (Fig. 2C).

Attitudes to prenatal diagnosis and medical abortions were neither influenced by a positive history of genetic disease in the family, nor religion, nor gender.

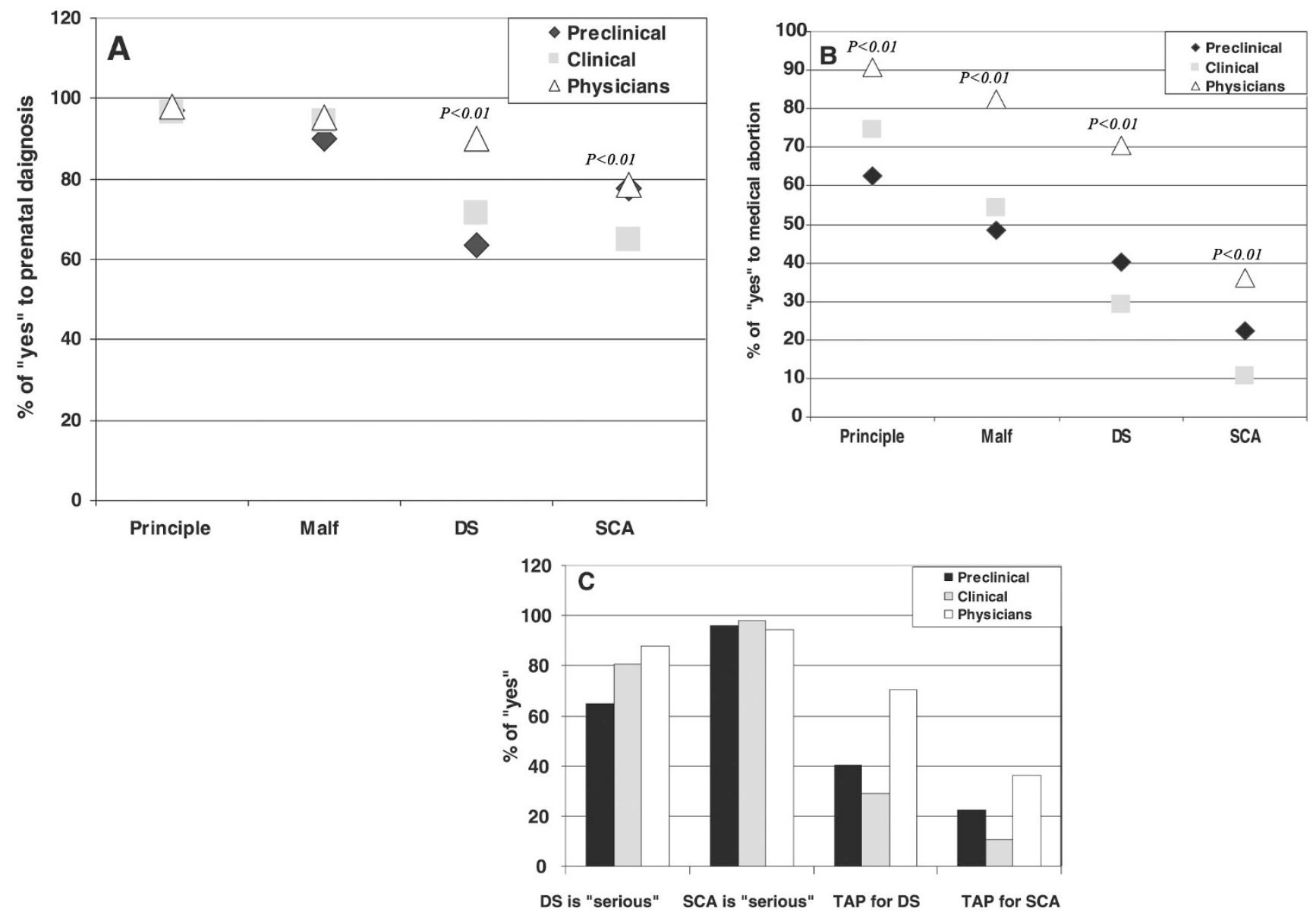

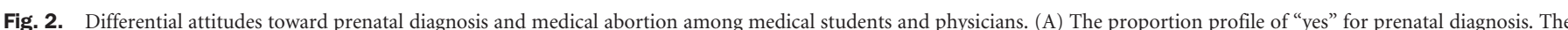

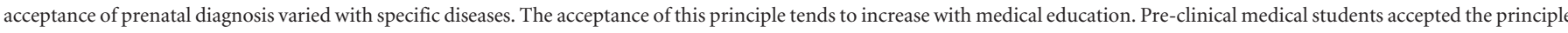

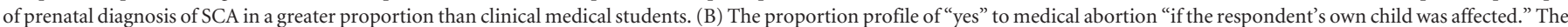

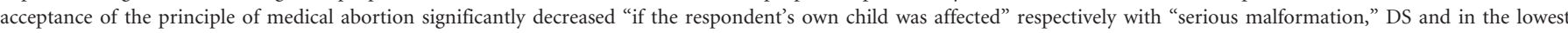

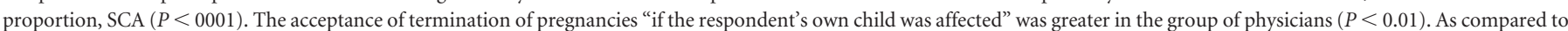

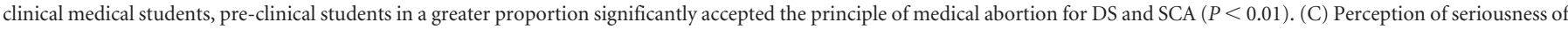

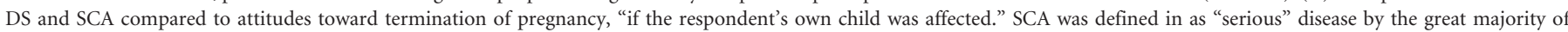

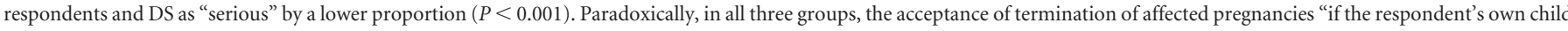
was affected" was lower for SCA than DS $(P<0.001)$. 


\section{DISCUSSION}

Cameroon is a sub-Saharan country with a population of about 16 million inhabitants. The country spans almost equally in two main geographical zones: the equatorial rain forest in the south and the tropical savanna and the Sahel region in the north. The health-care system of the country is organized into the public, private and traditional sectors. There is no universal medical insurance coverage in Cameroon. Traditional healers are very active. ${ }^{8}$ In addition to communicable diseases like malaria, HIV-AIDS and TB, Cameroon, like most developing countries is facing an epidemiologic transition with an increasing and recognized burden of chronic noncommunicable diseases, some of which are of genetic origin. Cameroon recently validated a national strategic plan for the control of sickle cell disease. The whole population is deserved by a total of 1,500 physicians, who practice mostly in public hospitals. The majority physicians are trainees of the unique medical school of the country, which trains about eighty medical students yearly. To the best of our knowledge, the present study is the first survey in Cameroon, and the first attempt in sub-Saharan Africa, to explore medical genetics knowledge, attitudes toward genetic counseling, genetic testing, prenatal and medical termination of pregnancy. The predominant male gender was similar to the expected ratio male/female medical students or physician in Cameroon at the time of the study. The majority of Christians was expected from the ratio Christian /Muslim among medical students or physicians, but not representative of general population. Indeed, about half of the Cameroonians living in the northern part of the country who are mostly Muslims, are nomadic with a lower level of education and socioeconomic development. The poverty index (based on illiteracy, housing, and chronic malnutrition) in the northern (Sahelian) zone is higher than in the south where the majority defined themselves as Christians. ${ }^{8}$

The response rate is relatively low, especially for physicians. In a previous study in the USA, randomly selected physicians and geneticists were mailed a questionnaire concerning genetics knowledge and attitudes, a \$25 incentive and intensive follow-up, raise the response rate from $19.6 \%(\mathrm{~N}=69)$ in the pilot test to $64.8 \%(\mathrm{~N}=1140)$ in the final survey. ${ }^{9}$ In the present study, our methodology offered the possibility to bypass the financial and the structural obstacles of such a study design. Indeed, the postal and telephone service are so limited or inefficient in Cameroon that they could not be used for our study. In addition, health professionals in developing countries are more involved in solving basic and enormous medical problems due to an overload of clinical activity, ${ }^{4}$ and may have lacked the time and motivation to complete a mailed study format. Despite these limitations, we think that our methods were valuable tools to produce a random range of physicians within a limited time. Furthermore, with open-ended questions, the respondent's answers were more likely to reflect the most prominent issues in their minds or practice. ${ }^{10}$ There are several reasons to suspect that our results represent the bestcase scenario. Indeed, physicians who completed this survey may have a greater interest in continuing medical education since they were attending the postgraduate continuing medical education conference.

Hemoglobinopathies were the most cited genetic disorder and this is in accordance with the general epidemiology of many lower-resource countries where there is a high prevalence of common red blood cell disorders. ${ }^{11}$ The diseases cited might give several clues on what genetic conditions would need specific attention, in the perspective of planning further genetic epidemiology research in Cameroon. SCA was by far the most prevalent genetic disease in respondent's families, career frequency ranges $8-34 \%$ in Cameroon. ${ }^{12}$ Moreover, oculocutaneous albinism which was the fourth genetic condition cited, was the second most common inheritable genetic disease in respondents' families. Oculocutaneous albinism is one of the most common autosomal recessive conditions in people of African decent. ${ }^{13}$ Surprisingly hemophilia, which is not as common as hemoglobonopathies, was cited by $57.5 \%$ of the respondents. We may have attributed this to the bias of the study format, but only two respondents cited HD, which was written on the study format as well. Thus, genetic diseases spontaneously cited may also reflect the teaching background of genetic disorders in the medical school.

SCA and karyotyping in general may represent an excellent point of entry of genetic science in developing countries. ${ }^{4} \mathrm{~A}$ specific positive finding was that the majority, especially preclinical students, knew the autosomal recessive mode of inheritance of SCA. This is essential for proper patient counseling. Similar results were found in a pilot study comparing the level of SCA knowledge in student (non-medical) from the University in Southeastern Texas (US) and the University in Enugu (Nigeria): participants' response to the question concerning the definition and transmission of SCA was $85 \%$ and $90 \%$ correct, respectively. ${ }^{14}$

The majority gave a correct answer concerning the diagnostic method of SCA and hemophilia, but very few or none considered DNA-based tests that have implication in prenatal diagnosis as an alternative. This may reflect the fact that physicians and future physicians do not have the use of genetic techniques for the purpose of diagnosis in mind, since there are no genetic testing laboratories in Cameroon. This may also appears to be a reflection of the absence of specific education about prenatal diagnosis for SCA in the Medical School curriculum, as well as absence of CME courses in medical genetics that are offered to clinicians in practice in Cameroon. The first CME course on prenatal genetics diagnosis was organized for gynecologists some two years ago. To our best knowledge, the nearest prenatal diagnosis service for SCA was established recently in Nigeria, the country neighboring country Cameroon to the west. ${ }^{15}$ Nevertheless, even in Nigeria, knowledge of where facilities for prenatal diagnosis are obtainable among health professionals and students is still lacking. ${ }^{16}$ Even when affordable, very rarely do Cameroonian patients (or samples) travel to Europe for genetics analysis.

Indeed, very few respondents had been in contact with karyotype or DNA analysis. However, several studies in devel- 
oped countries also demonstrate deficiencies in primary care physician knowledge of genetic and related practice skills. ${ }^{17,18,19}$ Mountcastle-Sha and Holzman postulated that, primary care physicians' participation in clinical research could present a teachable moment leading to both improvement of genetic knowledge and appropriate practice. ${ }^{20}$ Transferring genetic technology in lower-resource countries may not only offer exciting research opportunities, ${ }^{4}$ more importantly, physicians who participate in genetic research may constitute a core group of educational influence within their communities. ${ }^{21}$ Smallscale efforts comparable to Geneva-Yaoundé cooperation which contribute to train a Cameroonian medical geneticist, could serve as a useful model for universities with an interest in contributing to education in poorer nations. ${ }^{22}$ In 2003, the African Society of Human Genetics (AfSHG) was established. The aim of AfSHG is to equip the African scientific community and policy-makers with the information and practical knowledge needed to contribute to the field of genetics research and to attract global attention to the efforts of African scientists. ${ }^{23}$

The strong positive views of physicians on the role of genetic counseling, prenatal diagnosis and medical abortion, may be linked to their experience with affected patients and the psycho-social or economic impacts of several genetic conditions on families. In a similar study in Sri Lanka, demographic and experiential factors were associated with an increased acceptance of the principle of prenatal diagnosis and termination of affected pregnancy. ${ }^{24}$ In a recent study, a vast majority of African-American pre-clinical medical students supported genetic testing for preventive care (95\%). However, several concerns were expressed, including fears that abortion (51\%), and eugenics $(37 \%)$ will become more common. These concerns were increased, not lessened, by exposure to genetics education. ${ }^{7}$ In our study comparing pre-clinical medical students, a significantly lower proportion of clinical students accepted the termination of affected DS and SCA pregnancy. Although, African-American and Cameroonian medical students are not absolutely comparable in terms of the medical curriculum or socio-economic environment, to some extent, one can suspect a similar historical and cultural background to explain sensitivity to ethical concerns of preventive genetics testing. It is possible that the Cameroonian clinical medical students were sensitized in medical school and recognize the actual benefits of medical care and the ethical principles that guide clinical practice, but they have a limited clinical and practice experience when compared to MDs.

An unexpected finding of the present study was that SCA was considered out of the three groups a "serious" disease by the great majority of respondents, and DS as "serious" by a lower proportion. Paradoxically, in all the three groups, the acceptance of termination of affected pregnancies was lower for SCA than DS. The finding contrasted with the relatively high proportion of acceptance of the principle of prenatal diagnosis for SCA. The words "serious" and "grave" appear close to the word genetic in many US state laws, as criteria for availability or support of genetics services, including prenatal diagnosis and abortion. ${ }^{10}$ Wertz and Knoppers showed that, there is not sufficient consensus among experienced genetics professionals to define serious genetic conditions for purposes of law or policy: $46 \%$ of conditions listed as serious were also listed as not serious and $41 \%$ were listed as lethal. ${ }^{10}$ The main reasons for the perception of seriousness of DS and SCA need to be further analyzed in our cohort: the burden of handicap in DS as compared to that of SCA may be determinant, or the respondent's personal experience with a relative or a friend affected with SCA, which is prevalent in the respondents families and in the general population, or the fact that these well informed students and physicians may have taken into account, the progress in pathogenesis and treatment of SCA. ${ }^{25}$ To some extent, this attitude can be compared to that of Nigerian SCA female patients, who in more than $85 \%$, would like prenatal diagnosis to be offered in Nigeria, but only $35 \%$ would opt for termination of an affected pregnancy. ${ }^{26} \mathrm{Simi}-$ larly, $78 \%$ of educated Nigerians would want prenatal diagnosis started in Nigeria and only $45 \%$ would opt for termination of affected pregnancy. ${ }^{27}$ Although we do know that what people say they would do before the fact does not always predict what they actually choose to do when faced with a real decision, an evaluation of these attitudes might still give us an idea on how to initiate policy.

We need more information on whether the attitudes of medical students and doctors are comparable to that of some specific groups in the population like mothers and fathers with a SCD affected child. In addition, focus group studies might give a more detailed insight into the range of moral, legal and social concerns that the lay public holds about genetic technology. ${ }^{5}$ Pre-clinical medical students may draw an initial view from that of the educated group in the general population. ${ }^{7}$ Respondents are mostly below 40, thus most likely to be energetic and adaptable, and will be the decision-makers and teachers of the next 30 years. Investing now in their medical genetics education and research skills will influence the scientific potential for generations to come. An evaluation of the number of published scientific papers from 1997-2001 from sub-Saharan African countries, ranked the Republic of Cameroon fifth. ${ }^{28}$ This could be considered a positive background for introducing a challenging field like medical genetics to the country.

In conclusion, the results suggest an acceptable level of knowledge of clinical genetics although the awareness of DNA diagnosis seems poor. This cohort of students and doctors appears to accept the principles of clinical genetics involving counseling, prenatal diagnosis and in some cases termination of pregnancy. Given the high level of acceptance of prenatal diagnosis, a paradox exists between the lower acceptance of medical abortion for SCA, perceived as a severe disorder, and the greater acceptance of medical abortion for DS, which was perceived as a less severe condition. This emphasizes a need to develop medical research, and later research on ethics, social implications of medical genetics in this part of sub-Saharan Africa. Greater emphasis is needed at all levels of medical education to improve medical school courses in genetics, with the 
aim of optimizing the knowledge level of physicians as more genetic tests become available.

\section{ACKNOWLEDGMENTS}

For their input, we thank the medical students and doctors who participated in the survey. We also thank the Division of Medical Genetics, University Medical Centre and Geneva University Hospital, the Cameroon National Medical Conference organizers and the Switzerland-Cameroon Cooperation for the training grant in medical genetics, awarded to the first author of the present article.

\section{References}

1. Collins FS. Shattuck lecture-medical and societal consequences of the Human Genome Project. N Engl J Med 1999;341:28-37.

2. Bloom BR, Trach DD. Genetics and developing countries. BMJ 2001;322:10061007.

3. Advisory Committee on Health Research. Genomics and World Health. Geneva: World Health Organization, 2002.

4. Alwan A, Modell B. Recommendations for introducing genetics services in developing countries. Nat Rev Genet 2003;4:61-68.

5. Condit C. What is 'public opinion' about genetics? Nat Rev Genet 2001;2:811-815

6. Hunter A, Wright $\mathrm{P}$, Cappelli $\mathrm{M}$, et al. Physician knowledge and attitudes toward molecular genetic (DNA) testing of their patients. Clin Genet 1998;53:447-455.

7. Laskey SL, Williams J, Pierre-Louis J, et al. Attitudes of African-American premedical students toward genetic testing and screening. Genet Med 2003;5:49-54.

8. The World Bank. Cameroon: Diversity, Growth and Poverty Reduction: World Bank, 1995; viii, ix, 31:50-53.

9. Tambor ES, Chase GA, Faden RR, et al. Improving response rates through incentive and follow-up: the effect on a survey of physicians' knowledge of genetics. Am J Public Health 1993;83:1599-1603.

10. Wertz DC, Knoppers BM. Serious genetic disorders: can or should they be defined? Am J Med Genet 2002;108:29-35.

11. Guidelines for control of hemoglobin Disorders. WHO/HDP/HB/GL/94.1 Geneva: World Health Organization, 1994.

12. Weatherall DJ, Clegg JB. Inherited haemoglobin disorders: an increasing global health problem. Bull World Health Organ 2001;79:704-712.
13. Stevens G, Ramsay M, Jenkins T. Oculocutaneous albinism (OCA2) in sub-Saharan Africa: distribution of the common 2.7-kb P gene deletion mutation. Hum Genet 1997;99:523-527.

14. Ogamdi SO, Onwe F. A pilot study comparing the level of sickle cell disease knowledge in a university in southeastern Texas and a university in Enugu, Enugu State, Nigeria, West Africa. Ethn Dis 2000;10:232-236.

15. Akinyanju OO, Disu RF, Akinde JA, et al. Initiation of prenatal diagnosis of sicklecell disorders in Africa. Prenat Diagn 1999;19:299-304.

16. Kagu MB, Abjah UA, Ahmed SG. Awareness and acceptability of prenatal diagnosis of sickle cell anaemia among health professionals and students in North Eastern Nigeria. Niger J Med 2004;13:48-51.

17. Giardiello FM, Brensinger JD, Petersen GM, et al. The use and interpretation of commercial APC gene testing for familial adenomatous polyposis. $N$ Engl J Med 1997;336:823-827.

18. James C, Geller G, Bernhardt BA, et al. Are practicing and future physicians prepared to obtain informed consent? The case of genetic testing for susceptibility to breast cancer. Community Genet 1998;1:203-212.

19. Hayflick SJ, Eiff MP, Carpenter L, et al. Primary care physicians' utilization and perceptions of genetics services. Genet Med 1998;1:13-21.

20. Mountcastle-Shah E, Holtzman NA. Primary care physicians' perceptions of barriers to genetic testing and their willingness to participate in research. Am J Med Genet 2000;94:409-416.

21. Davis DA, Thomson MA, Oxman AD, et al. Changing physician performance. A systematic review of the effect of continuing medical education strategies. Jama 1995;274:700-705.

22. Gerber U. A small-scale foreign aid strategy. Science 2005;307:1410.

23. Rotimi CN. Inauguration of the African Society of Hum Genet. Nat Genet 2004;36: 544.

24. Jayasekara RW. The attitudes of doctors and students toward a genetic service in an Asian country: Sri Lanka. Asia Oceania J Obstet Gynaecol 1989;15:267-270.

25. Steinberg $\mathrm{MH}$, Brugnara C. Pathophysiological-based approaches to treatment of sickle cell disease. Annu Rev Med 2003;54:89-112.

26. Durosinmi MA, Odebiyi AI, Adediran IA, et al. Acceptability of prenatal diagnosis of sickle cell anaemia (SCA) by female patients and parents of SCA patients in Nigeria. Soc Sci Med 1995;41:433-436.

27. Durosinmi MA, Odebiyi AI, Akinola NO, et al. Acceptability of prenatal diagnosis of sickle cell anaemia by a sample of the Nigerian population. Afr J Med Med Sci 1997;26:55-58

28. Jaffe S. Back to Africa: yes it is possible to do science in Africa, but it's not that easy. The scientist 2002;16:48-50. 